not a eulogy, and for their benefit it is necessary to point out anything that appears to be a defect. The question of one or two volumes for a long work is always a matter of controversy; separate volumes are easier to hold-on the other hand, if one reads in bed or in a train, unless one takes both volumes one usually finds that what one wants is in the other volume. Whether two volumes are a good or a bad thing may be a matter of opinion, but it seems essential that each volume should have an index. A method employed in a popular textbook of surgery that appeared for a time in two volumes was to have one index covering both volumes, but the index was published identically at the end of each volume. In the work under review the index is only published at the end of Volume II, and if one has taken Volume I alone to bed or on a journey, one has no index. On the whole, I think the advantages of a single book outweigh those of separate volumes. It is possible, of course, that demand for publication made it necessary to publish what was ready as a first volume, before the whole work was completed, and this would explain the absence of an index in Volume I.

The main outline of the book follows previous editions. The dangers of prolonged weight traction, and the necessity for rapid reduction of deformity, to which Girdlestone recently drew attention, are emphasised here also. In dealing with the extension treatment of fractured femurs reference is made to the sliding bed and its considerable advantages, yet in all the illustrations in the chapter on injuries of the thigh it is obvious that the sliding bed is not employed. The reviewer found that when as the result of very satisfactory personal experience of its use, he introduced it into a hospital, it never "caught on," and was kept for nurses' lectures, and the residents did not use it. One wonders why this conservative reaction is so strong, and Figs. 1025 and 1027-28 are therefore particularly interesting as illustrating this outlook.

Nowadays there is a tendency to be unable to work whether as a surgeon or an anaesthetist, without the most elaborate apparatus, the inset picture in Fig. I035 will come, therefore, as a revelation to those whose experience is limited to well-established hospitals.

There is no need to deal with those descriptions of fractures and other injuries which have been so well dealt with in previous editions, and reappear with little change here. They have become the constant guide of both visiting staff and residents, and surely no higher praise can be given.

A word must be said, however, on "Rehabilitation," a word that has so great an advertisement value for any hospital that in many cases inadequate arrangements are hidden behind this magic word. Many so-called rehabilitation centres do not seem to make any great attempt to render a man fit to return to his previous occupation, and one wonders how much use, and what inspiration a locomotive driver, for instance, finds in making wool mats. Watson-Jones has really got down to it, as the opening remarks on this important subject show.

To those that have anything to do with rehabilitation this chapter should provide both inspiration and detailed instruction.

Watson-Jones quotes John Buchan "It is not enough to have specialists in physical diseases, the same man must in a sense be both. A good doctor should be, and indeed always has been, something of a psychologist." The value of competitive sport, and even a little mild gambling, as compared with dull exercises, is emphasised. How true is the statement "To sit on a bench hour after hour, lifting sandbags suspended from pulleys, is one of the deadliest and soul-destroying activities." Treating the patient as a whole is further shown by the statement "Cycling is another non-weightbearing exercise of value in knee-joint cases; but it must be emphasised that half-a-dozen bicycles that can be driven through the country are worth scores of fixed bicycles in a gymnasium. Nowadays one is asked "Is your journey really necessary?" If anyone is interested in the setting up of a rehabilitation centre, a journey to see a centre as described in this book would appear to be not only necessary, but essential.

One can predict that this will be the standard work on fractures and joint injuries for many years to come.

\section{SURGERY OF MODERN WARFARE}

Edited by Hamilton BaIley. Third Edition, Parts I, II and III. E. \& S. Livingstone, Edinburgh, 1944. Price I5s. each part.

The fact that already this work has reached its third edition in three years is sufficient proof of its popularity. The popularity of issuing a book in parts will be disputed by many. There is always the risk that the part one wants is elsewhere, and the absence of an index in the parts so far available is a handicap. The book is superbly illustrated, and the Editor believes in "window dressing" to lure readers to sample his wares. Chapter I, which caused the Editor so much trouble, is really in this category, for it is difficult to see the surgical value of the illustrations of a German machine gun in action, or of the other illustrations and information in this chapter. Nevertheless, I am prepared to defend this window dressing, for I found the work very attractive, and found myself picking up the book with the intention of "glancing at it" only to find that I had read a chapter or two with complete absorption before I realised what I had done!

Some surgical works are so unattractive that the mere making a resolve to read them is in itself an effort. One notes with amazement that the Medical Director-Generals of the Royal Navy and the Royal Air Force gave every facility and cooperation, whereas the Army authorities were not only non-co-operative but obstructive. This would appear to be a criticism of the Army medical service rather than a reflection upon this popular work. One cannot help feeling that constructive criticism and willing co-operation would have been more in line with the national effort towards victory.

Coming down to detailed criticism, Chapters VII to XIV need rearrangement and co-ordination. Oxygen therapy is dealt with in Chapter VII, but the reader will only find details of its technique if he pursues his studies to Chapter XIV.

In dealing with blood transfusion, the average reader would probably like to know in simple language a slight explanation of the expression "Rhesus factor," which to many appears a most. mysterious rumour!

In Part II, chapters on burns by such authorities as Wakely and McIndoe will prove of the greatest. value. The chapter by Bunyan is a bit "sketchy," and the details of irrigation rather inadequate. 
I would commend to the Editor the coloured film prepared at the Middlesex Hospital showing the treatment of burns with the simplest of apparatus -an irrigator, water-soluble sulphonamide cream and oil silk dressings, a simple technique that needs little skilled attention, and to the value of which the reviewer can testify.

A good deal of Part II is occupied by descriptions of anaesthetic apparatus, but nowadays a surgeon scarcely dares criticise anaesthesia, even though his efforts may be frustrated by its defects. On the other hand, it must be readily admitted that many operations are not only rendered feasible but even comparatively easy because of the great advances that have been made in the administration of anaesthetics. The Oxford inhaler is an ingenious gadget with its use of the phenomena of latent heat.

It is a matter of regret that in the very excellent articles on wound treatment, the use of Penicillin is scarcely touched upon. Perhaps in future editions, or even in the appendix, it may be possible to obtain an article by one of the military surgeons who has had experience in its use.

Fig. 273 ought to be replaced by one either showing the instruments covered by a sterile towel, or the nurse's mouth and nose covered by a "sprayproof" mask. It seems inevitable that in any hospital ward dressings must be done, and the trolley system, like so many other institutions, can be improved without necessarily being scrapped.

In Part III, the chapter on Heparin is especially interesting as being rather ahead of time, since many of the conclusions are the result of animal experiments that so far have not been confirmed in man.

The loss of Sir de Courcy Wheeler will be a blow to the Editors, for he was a lucid writer with an original outlook.

In criticising the article on the Thomas's splint, one regrets the absence of the use of a foot-piece to prevent the heel resting on the bed, with consequent displacement of the foot forward in the splint.

The chapter on amputations shows originality and an independence of the limb makers, but whether this will make for the comfort of the patient may be disputed.

In spite of the advocacy of weight-bearing stumps they seem to give their owners a lot of trouble. Whether this is due to faulty limb fitting is worth considering in the light of American experience.

In future editions it is to be hoped that the chapter on amputations, which, in its ultimate results, may be the most important of all chapters, will be entrusted to a surgeon who has had considerable experience at Roehampton, but who, as Elmslie always urged, is willing to co-operate with, but not to be dominated by, the limb fitters.

This work will be of the greatest service to all who have to deal with war wounds, whether as young surgeons starting their career, or old ones manning the "home front," and the remaining parts will be welcomed with eagerness.

\section{PREVENTION AND TREATMENT OF DISEASES IN WARM CLIMATES}

By T. Gerald Garry, M.B.E., M.D. Medical Publications, London. 1944. Price 8s. 6d.

This concise little book sets out to inform the lay public about the prevention and treatment of Tropical Diseases.
It is no easy task for any author to present a technical subject in language easily grasped by all. Dr. Garry has largely succeeded by presenting the subject in two parts. Part I deals with such vital points as food, water, exercise, clothing and personal preventive measures against tropical disease, while Part 2 gives a brief up-to-date review in simple language of the diseases most commonly encountered.

This little book links in an admirable way with the Synopsis of Tropical Medicine published in 1943 by Sir Philip Manson-Bahr in response to requests for a guide to Tropical Medicine in condensed form.

It is a pity that Dr. Garry has made no reference to Relapsing Fever, and to the recently discovered D.D.T. fumigation method against lice, bugs, fleas and other insect pests. Nor does he stress sufficiently the use of Pyrethrum spraying as a malaria preventive measure. A reference to the recently introduced water-filter canvas bag for individual serving soldiers could well find a place in future editions and no up-to-date book, however small, should omit a reference to Penicillin.

Apart from these minor omissions, readers of the Journal who are likely to be proceeding eastward are advised to read Dr. Garry's little book, for they will glean many useful, practical hints not usually contained in more stereotyped text books.

\section{DISEASES OF THE NOSE, THROAT AND EAR 3rd Edition}

By I. Samson Hall. E. w S. Livingstone, Edinburgh. 1944. Price I5s. net.

A third edition of Diseases of the Nose, Throat and Ear by Dr. Simson Hall within a few years is sufficient indication of its popularity. The book is of a size which should recommend it to students, being, as prescribed also for a lady's dress, short but long enough to cover the subject. The student will find all that be can reasonably be expected to know, and the advice given is always based on sound practice, though sometimes lacking the detail for which a book of reference may be required. Some inaccuracies which had found their way into earlier editions have been corrected. There are, however, places which might still be improved. The descriptions for example of the rare condition of Pemphigris of the Pharynx and Pachydermia of the Larynx do not compensate for their extreme brevity by an irreproachable precision. The description of tracheotomy, which does not differentiate between an emergency in childhood and the deliberate procedure which can usually be adopted for an adult, will not be very helpful to the house surgeon either in the execution or after-treatment of this vital operation. For sections on the Accessory Sinuses of the Nose, and on the Ear, the diseases of which provide so large a part of the work in a special department, high praise must be given for the accurate descriptions. A fuller account of the cerebrospinal fluid and the changes which it undergoes in the intracranial complications is needed however.

This book has now established itself as a student's favourite, a position which it duly merits, and we desire only to indicate a few directions in which further improvement is possible. It may not be out of place, therefore, also to remind the author that menthol can no longer be obtained, and it is doubtful whether its absence from the dispenser's list of drugs has deprived patients of any comfort. 